\title{
Reuso da água da chuva na produção de blocos de concreto não estrutural
}

\author{
Rain water reuse in the production of non-structural concrete blocks
}

\author{
João Paulo Gama de Oliveira ${ }^{1}$; Luana Celeste Silva ${ }^{2}$; Fernando A. da S. Fernandes ${ }^{3}$ e \\ Lidiane A. F. da Paz \\ ${ }^{1}$ Acadêmico de Engenharia Civil, Faculdade Católica do Tocantins, Palmas, TO, Brasil \\ ${ }^{2}$ Acadêmica de Engenharia Civil, Faculdade Católica do Tocantins, Palmas, TO, Brasil \\ 3Professor Mestre, Departamento de Engenharia Civil, Faculdade Católica do Tocantins, Palmas, TO, Brasil \\ ${ }^{4}$ Eng. Agrícola, Acadêmica de Engenharia Civil, Faculdade Católica do Tocantins, Palmas, TO, Brasil.
}

\begin{abstract}
Resumo
A água é essencial em todas as esferas da vida humana. Dentre elas a construção civil. Não considerada como material de construção, a água é consumida em grande escala nos canteiros de obra, concreteiras e na produção de blocos de concreto. O uso inteligente e alternativas sustentáveis reduzem o consumo e aliam progresso e produção limpa. O reuso da água da chuva se mostrou uma solução eficaz e lucrativa para uma fábrica de blocos de concreto não estrutural na cidade de Palmas, no estado do Tocantins. A água coletada e armazenada para este fim foi submetida a estudos que em primeiro estágio apontaram presença de corpos estranhos. Constatadas essas irregularidades através de peneiras e filtros eliminaram-se os corpos estranhos e tornou a água própria para a fabricação. Os estudos garantiram a qualidade da água, capaz de produzir blocos sem interferência em suas propriedades. O resultado foi viabilidade produtiva, redução de custos e produção sustentável.
\end{abstract}

Palavra-Chave: chuva, reuso de água, blocos de concreto, sustentabilidade.

\begin{abstract}
Water is essential in all spheres of human life. Among them the construction. Not considered as a building material, water is consumed on a large scale in construction sites, concrete producers and the production of concrete blocks. Clever use and sustainable alternatives reduce consumption and combine progress and cleaner production. The reuse of rainwater proved to be an effective and profitable solution to a factory of non-structural concrete blocks in the city of Palmas in Tocantins state. The water collected and stored for this purpose was subjected to studies that first stage showed the presence of foreign bodies. These irregularities detected through screens and filters to eliminate foreign bodies and made water itself to manufacture. Studies have ensured water quality, capable of producing without interference blocks on their properties. The result was productive feasibility, cost reduction and sustainable production.
\end{abstract}

Key words: rain, water reuse, concrete blocks, sustainability. 


\section{Introdução}

De grande importância para a manutenção da vida na terra, a água se torna um recurso natural valioso, inestimável e insubstituível. Cerca de $70 \%$ da superfície terrestre é coberta por água, porém menos de 3\% deste volume é de água doce (CORSAN, 2015), esta essencial para a sobrevivência humana. Pelo uso irresponsável e descompromisso com o meio ambiente, a água tem se tornado uma substância escassa e rara. A derrubada de árvores, as queimadas, o consumo exacerbado dos recursos naturais e a ganância colocaram em risco a vida de todas as espécies na terra. As constantes mudanças climáticas afetam o ciclo hidrológico colocando em desequilíbrio a manutenção da água. Em relatório publicado pela ONU (Organização das Nações Unidas) a previsão é de que em 2050 cerca de $45 \%$ da população mundial viverá sem a cota mínima diária de água.

É provável que o Brasil possua as maiores reservas de água do mundo. Estas reservas estão distribuídas em todo o Território Nacional, tendo sua maior porcentagem na Amazônia. Entretanto isso não impede que o país sofra com a falta d'água como tem acontecido com a grande São Paulo-SP que enfrenta a maior crise hídrica de sua história.

Em São Paulo, a crise hídrica já afeta quase metade da população: 20 milhões de pessoas de 68 municípios mais a capital. O Sistema Cantareira, que atende 9,8 milhões de paulistas, sendo 8,4 milhões só na capital, tem batido recordes negativos constantemente - na última quinta-feira, o reservatório atingiu 4,1\% de sua capacidade, segundo a Companhia de Saneamento Básico do Estado de São Paulo (Sabesp). Sem previsão de chuvas substanciais até os últimos dias de outubro, a estimativa é que a primeira parcela do volume morto, incorporada em 15 de maio, acabe em meados de novembro. (JULIANA SANTOS E BIANCA BIBIANO, Outubro/2014, Veja Online).

Diante dessa perspectiva, tendo em vista a importância desse recurso natural, a conscientização ambiental e o reuso da água podem significar melhoras para a sociedade e principalmente para o planeta.

Segundo a CETESB (Companhia Ambiental do Estado de São Paulo) deve-se considerar o reuso de água como parte de uma atividade mais abrangente que é o uso racional ou eficiente da água, o qual compreende também o controle de perdas e desperdícios, e a minimização da produção de efluentes e do consumo de água.

A Associação Brasileira de Normas Técnicas NBR 6136 define blocos de concreto como um elemento de alvenaria cuja área líquida é igual ou inferior a 75\% da área bruta. Essa mesma norma define que a água a ser usada deve ser limpa e isenta de produtos nocivos à hidratação do cimento. Este artigo vem apresentar uma alternativa inteligente ao uso de água na produção de blocos de concreto sem função estrutural: a captação e reutilização de água da chuva.

A água coletada da chuva, a partir de agora chamada águas pluviais deve ser ensaiada em laboratório a fim de verificação de $\mathrm{pH}$ e da presença de impurezas que comprometam sua qualidade. Esses ensaios são embasados na Norma Brasileira ABNT NBR 15900-2.

O Potencial Hidrogeniônico $(\mathrm{pH})$ consiste num índice que indica a acidez, neutralidade ou alcalinidade de um meio qualquer. Classificados: pH 0 a 7 - soluções ácidas; pH - 7 - soluções neutras; pH acima de 7 - soluções básicas ou alcalinas. (LIRIA ALVEZ, Brasil Escola Online).

É importante salientar que se tratando de água da chuva, a produção está sujeita a enfrentar dificuldades de acordo com o índice pluviométrico mensal da região. O índice pluviométrico é o volume de água que chove em determinado período. (DAE S.A. - Água e Esgoto, Online).

Fundamentados nas Normas Técnicas Brasileiras, a metodologia e resultado dos estudos realizados nas fábricas de blocos de concreto são apresentados ao decorrer deste artigo, assim como o levantamento de dados relevantes, organizados em forma de gráficos e tabelas para auxílio e melhor compreensão do assunto abordado.

\section{Metodologia}

REGET - V. 20, n. 1, jan.- abr. 2016, p.487-496 
Para realização deste trabalho, foi feita uma revisão na literatura existente que trata da água, buscando conhecimento acerca deste recurso e de sua disponibilidade para uso. Como se trata de água da chuva, um conhecimento sobre a precipitação pluviométrica da região também se fez necessária. Em auxílio, artigos e postagens online deram o suporte para a pesquisa.

Na sequência, foram realizadas visitas a duas fábricas de blocos de concreto não estrutural na cidade de Palmas, no Estado do Tocantins. Em uma delas (fábrica A) a água da chuva é tratada e reutilizada na confecção dos blocos, enquanto na outra (fábrica B) não há esse reaproveitamento. Os estudos foram concentrados apenas na fábrica A, e os dados obtidos na fábrica B foram utilizados para confecção de gráfico comparativo, visando à comprovação da viabilidade econômica do reuso da água da chuva.

A visita inicial a fábrica A teve como objetivo a identificação do sistema de coleta, tratamento e posterior utilização da água. A figura abaixo, elaborada com o auxílio do software de computação gráfica AutoCAD® apresenta a solução utilizada para a captação, armazenamento e tratamento da água.

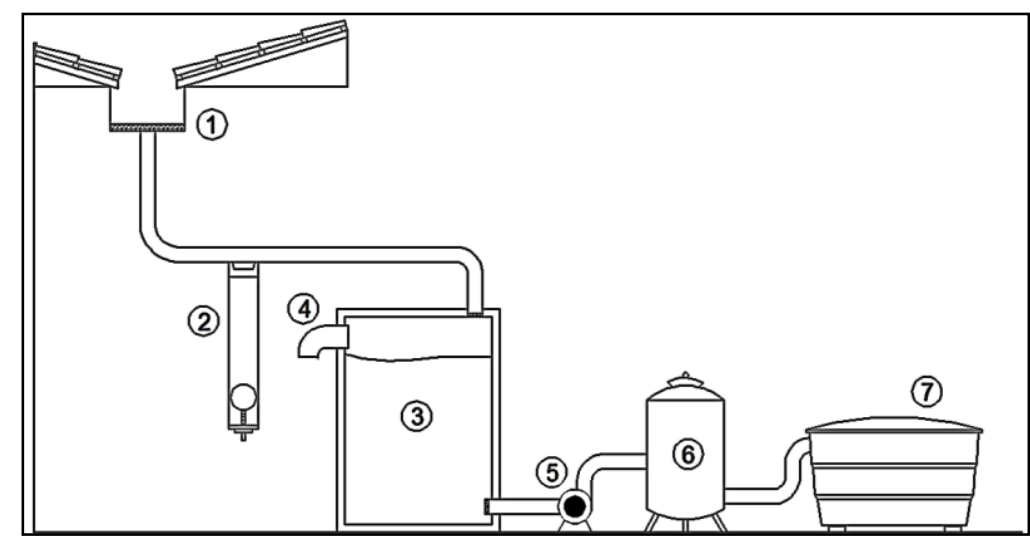

Figura 1 - Sistema de captação e tratamento da água não ilustrados em medidas reais. Representação elaborada com o uso do software AutoCAD ${ }^{\circledR}$

O sistema de captação de água da chuva se divide conforme as etapas abaixo:

1. Calha e crivo de $2 \mathrm{~mm}$ (para filtração de impurezas);

2. Separador de fluxo (descarte da água inutilizável);

3. Reservatório 1 (decantação);

4. Extravasor de água (para ocasiões esporádicas);

5. Bomba de recalque;

6. Filtro;

7. Caixa d'água (água pronta para ser utilizada na fabricação de blocos de concreto não estrutural).

A primeira água que cai na cobertura não pode ser utilizada, porque é impura e serve como uma água de "lavagem do telhado". Estima-se que a cada $100 \mathrm{~m}^{2}$ de telhado perde-se 20 litros de água inicial da chuva para esse processo de limpeza (SNatural \& Naturaltec, Online).

\subsection{A água da chuva}

Quando se fala em reuso de água da chuva é preciso ter ciência de que se está lidando com fatores externos e que independem de ações humanas para sua ocorrência. $O$ volume e ocorrência de chuvas não podem ser previstas com certeza absoluta, porém há fatores que auxiliam nas previsões e preparação para determinada época. Essa ferramenta de grande utilidade é o índice pluviométrico.

Com base em estudos publicados sobre o clima do estado do Tocantins, foi possível encontrar informações que auxiliaram nos cálculos de volume de água que se pode captar e reutilizar. Marcuzzo et al. (2011), utilizando os dados de Pinto et al. (2011), executou a análise dos totais mensais das médias históricas de 1977 à 2006 de 34 estações, para o bioma do Cerrado do Tocantins, conforme o 
histograma da Figura 2 dividiu-se a sazonalidade do ano hidrológico em período úmido começando em outubro e terminando em abril e período seco começando em maio e terminando em setembro.

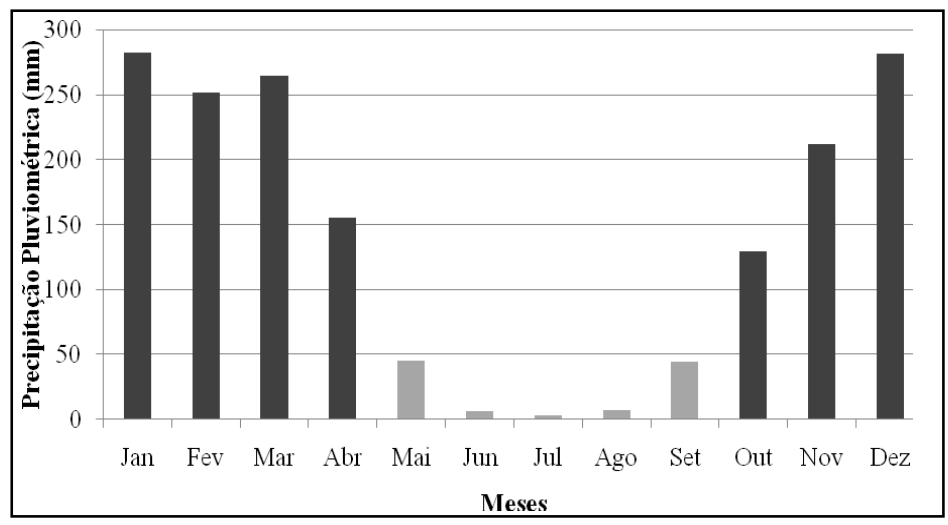

Figura 2 - Histograma dos totais médios mensais de precipitação pluviométrica no bioma do Cerrado do estado do Tocantins, referente ao período histórico de 1977 à 2006 . Fonte: Marcuzzo et al. (2011)

\subsubsection{Cálculo do volume de chuvas}

Com o índice pluviométrico médio em mãos, pode-se então calcular o volume médio de água que o telhado em estudo seria capaz de coletar mensalmente.

Marcelo Rigonatto, especialista em Estatística e Modelagem Matemática em estudo publicado no site Brasil Escola concluiu que: dizer que em uma região choveu $100 \mathrm{~mm}$ significa dizer que em uma área de $1 \mathrm{~m}^{2}$, a lâmina de água formada pela chuva que caiu apresenta uma altura de 100 milímetros. Esse volume pode ser obtido calculando o volume do paralelepípedo de $1 \mathrm{~m}^{2}$ de área da base e altura de $100 \mathrm{~mm}=0,1$ metros.

Portanto, para cálculos de volume precipitado considera-se a área de captação e altura ( $\mathrm{mm}$ de chuva): $\mathrm{V}=\mathrm{A} \times \mathrm{h}$.

Como a área do telhado é de $375 \mathrm{~m}^{2}$ e a média pluviométrica para Janeiro, conforme a tabela 1 é de $0,28 \mathrm{~m}$, então o volume esperado é de 105000L. Tendo posse dos dados, é possível ter uma previsão média de quantos litros o telhado em estudo poderá captar, observando os índices pluviométricos para cada mês. Tem-se então a seguinte previsão:

Tabela 1 - Quantidade esperada de litros captados pelo telhado em estudo com base no índice pluviométrico médio para a região

\begin{tabular}{c|c|c|c|c}
\hline Mês & $\begin{array}{c}\text { Índice } \\
\text { Pluviométrico (m) }\end{array}$ & $\begin{array}{c}\text { Área do } \\
\text { Telhado } \mathbf{( m}^{\mathbf{2}}\end{array}$ & $\begin{array}{c}\text { Quantidade } \\
\text { esperada (m) }\end{array}$ & $\begin{array}{c}\text { Quantidade } \\
\text { esperada (litros) }\end{array}$ \\
\hline Jan & 0,28 & 375 & 105 & 105000 \\
\hline Fev & 0,253 & 375 & 94,875 & 94875 \\
\hline Mar & 0,265 & 375 & 99,375 & 99375 \\
\hline Abr & 0,155 & 375 & 58,125 & 58125 \\
\hline Mai & 0,045 & 375 & 16,875 & 16875 \\
\hline Jun & 0,01 & 375 & 3,75 & 3750 \\
\hline Jul & 0,005 & 375 & 1,875 & 1875 \\
\hline Ago & 0,015 & 375 & 5,625 & 5625 \\
\hline Set & 0,043 & 375 & 16,125 & 16125 \\
\hline Out & 0,145 & 375 & 54,375 & 54375 \\
\hline Nov & 0,22 & 375 & 82,5 & 82500 \\
\hline Dez & 0,28 & 375 & 105 & 105000 \\
\hline
\end{tabular}


Conforme a Tabela 1, conclui-se que de Janeiro a Dezembro tem-se uma média de precipitação boa, 0,143m, sendo assim, espera-se aproximadamente uma média de 53625 litros de água em cada mês do ano. Considerando que na época mais crítica, no tempo da seca, não atingirá essas médias.
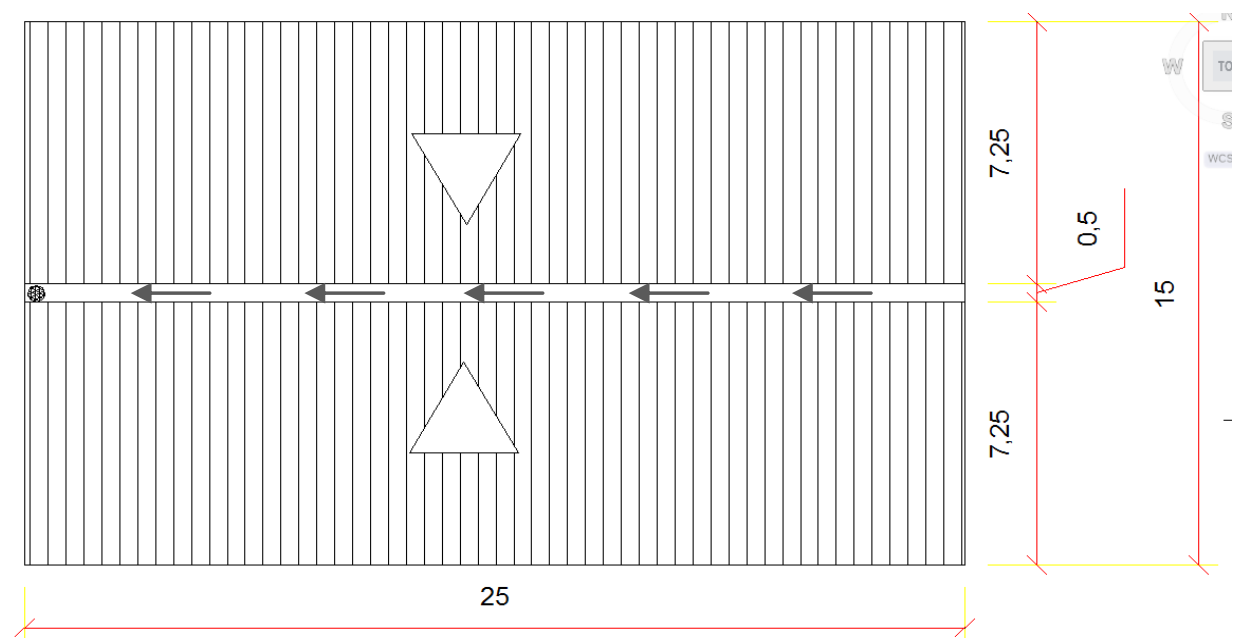

Figura 3 - Representação em medidas reais (m) do telhado usado para captação da água da chuva na fábrica A. Área total: $375 \mathrm{~m}^{2}$. Desenho elaborado com o uso do software AutoCAD®

\section{$2.2 \mathrm{O}$ consumo mensal médio}

Para essa etapa do estudo, questionários foram elaborados para fins de obtenção de informações importantes para a compreensão dos dados e melhor visibilidade do assunto tratado. Com esses questionários obtém-se dados importantes como a quantidade de água utilizada para a fabricação de determinada quantidade de blocos de concreto.

Tabela 02 - Consumo mensal em litros do ano de 2014 baseada na quantidade de dias trabalhados e litros consumidos por dia

\begin{tabular}{c|c|c|c|c}
\hline Mês/2014 & Dias úteis & $\begin{array}{c}\text { Litros consumidos } \\
\text { por dia }\end{array}$ & $\begin{array}{c}\text { Consumo mensal em } \\
\text { litros }\end{array}$ & $\begin{array}{c}\text { Consumo mensal } \\
\text { em }^{\mathbf{3}}\end{array}$ \\
\hline Jan & 26 & 850 & 22100 & 22,1 \\
\hline Fev & 21 & 850 & 17850 & 17,85 \\
\hline Mar & 26 & 850 & 22100 & 22,1 \\
\hline Abr & 24 & 850 & 20400 & 20,4 \\
\hline Mai & 26 & 1700 & 44200 & 44,2 \\
\hline Jun & 24 & 1700 & 40800 & 40,8 \\
\hline Jul & 27 & 1700 & 45900 & 45,9 \\
\hline Ago & 26 & 1700 & 44200 & 44,2 \\
\hline Set & 26 & 1700 & 44200 & 44,2 \\
\hline Out & 27 & 850 & 22950 & 22,95 \\
\hline Nov & 24 & 850 & 20400 & 20,4 \\
\hline Dez & 23 & 850 & 19500 & 19,5 \\
\hline
\end{tabular}




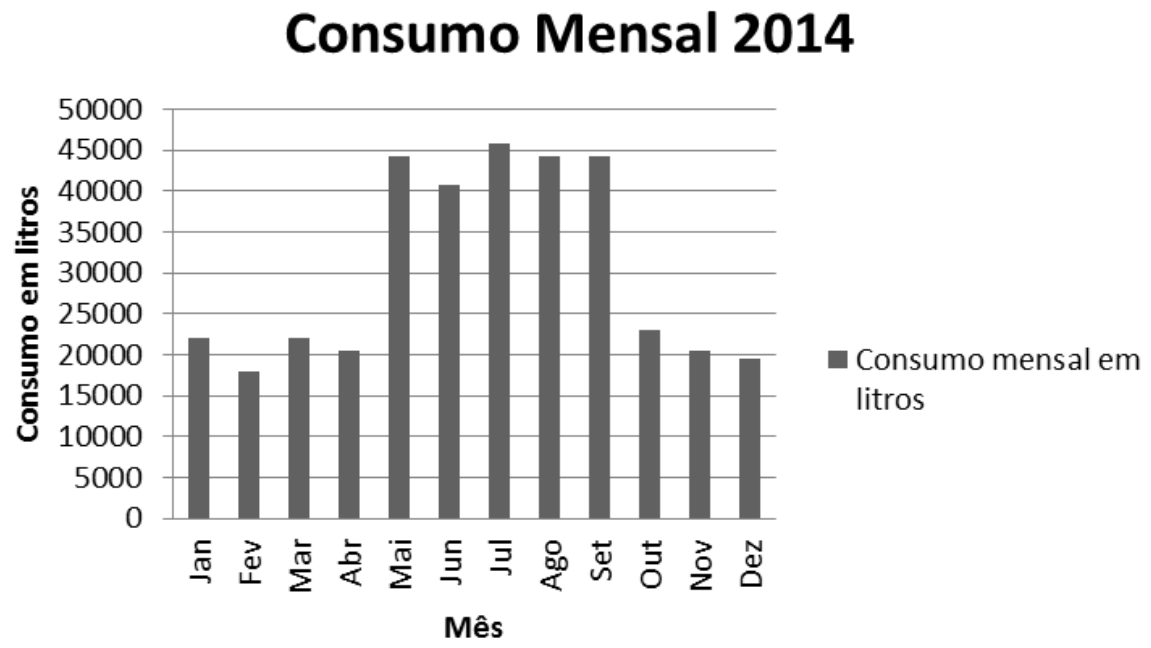

Figura 04 - Gráfico de consumo mensal do ano de 2014. Os valores correspondem apenas ao consumo de água com fins de produção de blocos de concreto. Gráfico elaborado na ferramenta Microsoft Excel for Windows

Estima-se que nos meses úmidos a cada 60 blocos produzidos tenha-se um consumo de 5 litros de água. No verão tocantinense (que compreende os meses de maio a setembro) essa mesma quantidade de blocos necessita de 10 litros de água. A produção diária de ambas as fábricas são em média de 9000 blocos de concreto, resultando em um total de aproximadamente 750 litros por dia. Entretanto, a água também é utilizada para a hidratação dos blocos recém fabricados por um período de 10 dias. Isso é necessário para garantir uma "cura" correta e que resulte em blocos de qualidade. São gastos por dia cerca de 100 litros de água com essa hidratação. Tem-se então que por dia são gastos 850 litros de água em uma média de 9000 blocos de concreto. Tendo-se em mente que no verão tocantinense o uso é dobrado, logo o gasto chegará aos 1700 litros diários. É importante observar que não está englobado aqui o gasto diário do consumo dos trabalhadores e dos sanitários, conforme pode ser verificado na Tabela 2 e na Figura 4.

\subsection{Viabilidade Econômica}

Nesta etapa do estudo foram coletados os dados das fábricas A e B referente ao gasto mensal com água durante o ano de 2014, sendo exclusivamente voltada para a produção de blocos de concreto. Desta maneira equiparamos os gastos com água para melhor resultado nas comparações. Os resultados são apresentados em forma de tabelas que auxiliaram na elaboração de um gráfico de comparação entre a fábrica $\mathrm{A}$ (que faz o reuso) e a fábrica B (que não reutiliza).

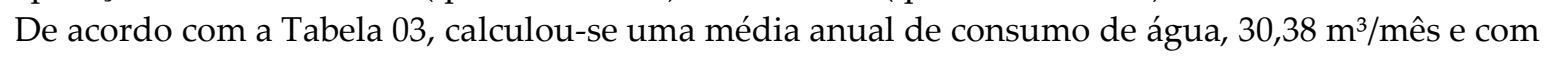
um gasto anual de $\mathrm{R} \$ 6333,21$.

Na fábrica A, que reutiliza água da chuva, além do gasto com água fornecida pela distribuidora há também um pequeno acréscimo na energia devido ao uso da bomba. Inclui-se então ao valor final da água, este acréscimo em relação à energia de forma que o resultado final é dado por: tarifa mensal da água + acréscimo de energia em relação à bomba. Para cálculo da energia utilizada pela bomba, levou-se em consideração o consumo diário em $\mathrm{kWh}$ e o tempo de funcionamento da mesma. 
Oliveira et al.: Reuso da água da chuva na produção de blocos de concreto não estrutural

Tabela 3 - Gasto mensal com água durante o ano de 2014 da Fábrica B. Não há o reuso da água da chuva

\begin{tabular}{l|r|c|c|c|c}
\hline Mês/2014 & $\begin{array}{r}\text { Dia } \\
\text { s úteis }\end{array}$ & $\begin{array}{c}\text { Gasto com água } \\
\left(\mathbf{m}^{3}\right)\end{array}$ & $\begin{array}{c}\text { Valor (sem } \\
\text { taxa de esgoto) } \\
\mathbf{( R \mathbf { } )}\end{array}$ & $\begin{array}{c}\text { Valor da taxa } \\
\text { de esgoto (R\$) }\end{array}$ & Total (R\$) \\
\hline Janeiro & 26 & 22,1 & 213,27 & 170,62 & 383,89 \\
\hline Fevereiro & 21 & 17,85 & 172,26 & 137,81 & 310,07 \\
\hline Março & 26 & 22,1 & 213,27 & 170,62 & 383,89 \\
\hline Abril & 24 & 20,4 & 196,86 & 157,49 & 354,35 \\
\hline Maio & 26 & 44,2 & 426,53 & 341,23 & 767,76 \\
\hline Junho & 24 & 40,8 & 393,72 & 314,98 & 708,7 \\
\hline Julho & 27 & 45,9 & 442,94 & 354,36 & 797,3 \\
\hline Agosto & 26 & 44,2 & 426,53 & 341,23 & 767,76 \\
\hline Setembro & 26 & 44,2 & 426,53 & 341,23 & 767,76 \\
\hline Outubro & 27 & 22,95 & 221,47 & 177,18 & 398,65 \\
\hline Novembro & 24 & 20,4 & 196,86 & 157,49 & 354,35 \\
\hline Dezembro & 23 & 19,5 & 188,18 & 150,55 & 338,73 \\
\hline
\end{tabular}

Tabela 4 - Consumo mensal de energia utilizada pela bomba da fábrica A no ano de 2014. Em relação ao reuso da água da chuva

\begin{tabular}{|c|c|c|c|c|c|c|c|c|}
\hline $\begin{array}{c}\text { Mês/201 } \\
4\end{array}$ & $\begin{array}{r}\text { Dia } \\
\mathrm{s} \text { úteis }\end{array}$ & $\begin{array}{l}\text { Consu } \\
\text { mo diário } \\
(\mathrm{kWh})\end{array}$ & $\begin{array}{r}\text { Consu } \\
\text { mo mensal } \\
(\mathbf{k W h})\end{array}$ & $\begin{array}{l}\text { Tempo de } \\
\text { uso da bomba } \\
\text { por dia (h) }\end{array}$ & $\begin{array}{l}\text { Quantida } \\
\text { de de vezes } \\
\text { em que a } \\
\text { bomba foi } \\
\text { utilizada }\end{array}$ & $\begin{array}{c}\text { Va } \\
\text { lor } \\
\text { mensal } \\
(\mathrm{R} \$)\end{array}$ & $\begin{array}{l}\text { Tributos } \\
\text { (R\$) }\end{array}$ & $\begin{array}{l}\text { Total } \\
\text { (R\$) }\end{array}$ \\
\hline Janeiro & 26 & 0,225 & 5,85 & 0,5 & 26 & $3^{3,7}$ & 13 & 16,73 \\
\hline Fevereir & 21 & 0,225 & 4,725 & 0,5 & 21 & $2^{3,0}$ & 10 & 13,02 \\
\hline Março & 26 & 0,225 & 5,85 & 0,5 & 26 & $\begin{array}{l}3,7 \\
3^{3}\end{array}$ & 13 & 16,73 \\
\hline Abril & 24 & 0,225 & 5,4 & 0,5 & 24 & $5^{3,4}$ & 13 & 16,45 \\
\hline Maio & 26 & 0,225 & 1,8 & 0,5 & 8 & $5^{1,1}$ & 6,08 & 7,23 \\
\hline Junho & 24 & 0,225 & 0,45 & 0,5 & 2 & $\begin{array}{l}0,2 \\
9^{0} \\
\end{array}$ & 2,02 & 2,31 \\
\hline Julho & 27 & 0,225 & 0,225 & 0,5 & 1 & $\begin{array}{l}0,1 \\
5^{0}\end{array}$ & 1,1 & 1,25 \\
\hline Agosto & 26 & 0,225 & 0,675 & 0,5 & 3 & $4^{0,4}$ & 4,33 & 4,77 \\
\hline $\begin{array}{ll} & \text { Setembr } \\
\text { o } & \\
\end{array}$ & 26 & 0,225 & 1,8 & 0,5 & 8 & $5^{1,1}$ & 6,08 & 7,23 \\
\hline Outubro & 27 & 0,225 & 6,075 & 0,5 & 27 & $\begin{array}{l}3,8 \\
8^{3,8} \\
\end{array}$ & 15 & 18,88 \\
\hline $\begin{array}{l}\text { Novemb } \\
\text { ro }\end{array}$ & 24 & 0,225 & 5,4 & 0,5 & 24 & $5^{3,4}$ & 13 & 16,45 \\
\hline $\begin{array}{l}\text { Dezemb } \\
\text { ro }\end{array}$ & 23 & 0,225 & 5,175 & 0,5 & 23 & 3,3 & 13 & 16,3 \\
\hline & & & & & & & $\begin{array}{l}\text { Gasto } \\
\text { Anual }\end{array}$ & 137,35 \\
\hline
\end{tabular}


Com os dados da rede elétrica foi possível a elaboração da tabela 04. Com todas as informações necessárias, torna-se possível então elaborar uma tabela de gasto mensal do ano de 2014 para a fábrica A, referente ao consumo da água com o acréscimo de energia.

Tabela 5 - Consumo mensal de água + energia da bomba do ano de 2014 para a fábrica A

\begin{tabular}{c|r|c|c|c|c|c}
\hline Mês & $\begin{array}{r}\text { Dia } \\
\text { s úteis }\end{array}$ & $\begin{array}{r}\text { Valor } \\
\text { energia (R\$) }\end{array}$ & $\begin{array}{c}\text { Água utilizada } \\
\text { da distribuidora } \\
\left(\mathbf{m}^{3}\right)\end{array}$ & $\begin{array}{r}\text { Valor } \\
\text { da taxa de } \\
\text { água (R\$) }\end{array}$ & $\begin{array}{c}\text { Valor da } \\
\text { taxa de esgoto } \\
\text { (R\$) }\end{array}$ & $\begin{array}{c}\text { Total } \\
\text { (R\$) }\end{array}$ \\
\hline Janeiro & 26 & 16,73 & 0 & 0 & 0 & 16,73 \\
\hline Fevereiro & 21 & 13,02 & 0 & 0 & 0 & 13,02 \\
\hline Março & 26 & 16,73 & 0 & 0 & 0 & 16,73 \\
\hline Abril & 24 & 16,45 & 0 & 0 & 0 & 16,45 \\
\hline Maio & 26 & 7,23 & 27,33 & 263,74 & 211 & 481,97 \\
\hline Junho & 24 & 2,31 & 37,05 & 357,54 & 286,04 & 645,89 \\
\hline Julho & 27 & 1,25 & 44,03 & 424,89 & 339,92 & 766,06 \\
\hline Agosto & 26 & 4,77 & 38,58 & 372,3 & 297,84 & 674,91 \\
\hline Setembro & 26 & 7,23 & 28,08 & 270,98 & 216,79 & 495 \\
\hline Outubro & 27 & 18,88 & 0 & 0 & 0 & 18,88 \\
\hline Novembro & 24 & 16,45 & 0 & 0 & 0 & 16,45 \\
\hline Dezembro & 23 & 16,3 & 0 & 0 & 0 & 16,3 \\
\hline & & & & & Gasto Anual & $3.178,39$ \\
\hline
\end{tabular}

Portanto, há um gasto de $\mathrm{R} \$ 3041,04$ de água e também pode-se verificar na Tabela 04 que há um gasto anual de $\mathrm{R} \$ 137,35$ com a energia da bomba de recalque. E conforme mostra a Tabela 05, o gasto total anual é de $\mathrm{R} \$ 3178,39$.

Apesar do investimento inicial com o sistema de coleta e tratamento, pode-se notar que há uma economia de 50,19\% ao ano. Os custos são reduzidos pela metade. Isso comprova a viabilidade econômica através de métodos sustentáveis que garantirão uma produção verde.

Com os dados corretamente calculados e correlacionados foi elaborado então um gráfico de comparação econômica entre as duas fábricas estudadas. A figura 05 demonstra o ganho que se tem ao reutilizar a água da chuva.

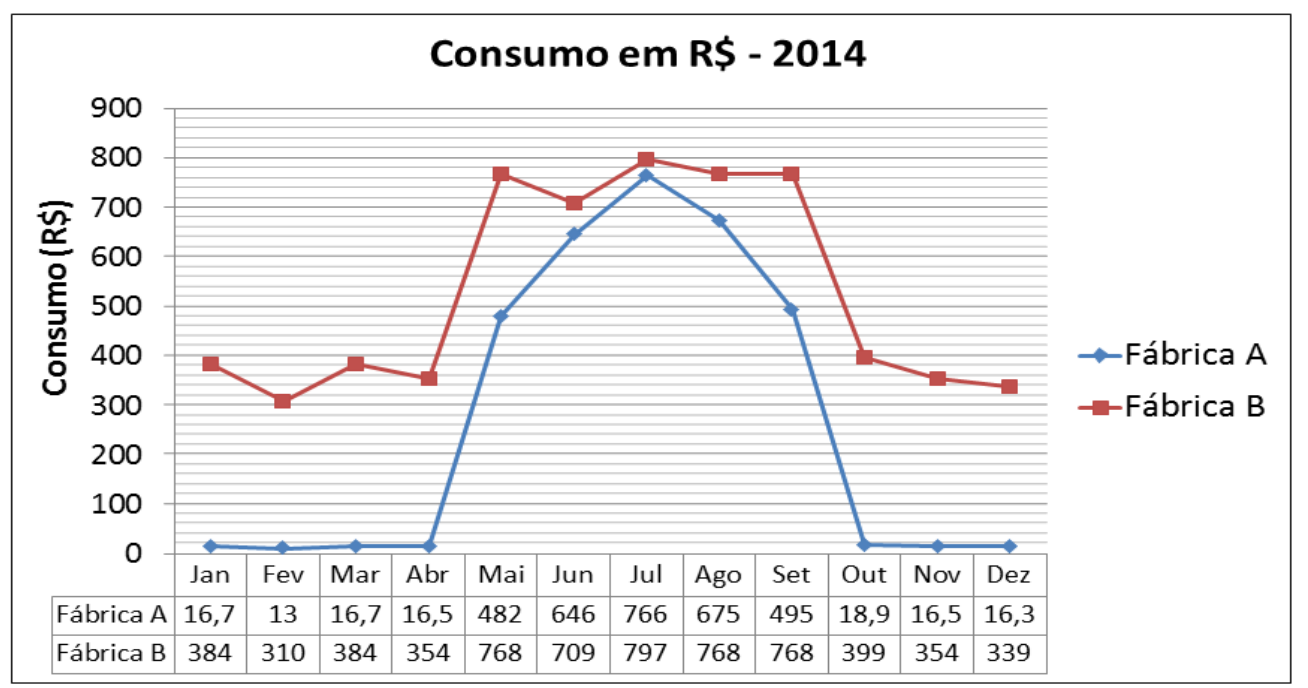

Figura 05 - Gráfico de comparação de custos com água na produção de blocos de concreto durante o ano de 2014. Valores arredondados automaticamente pelo software. Elaborado pelo Microsoft Excel for Windows. 


\subsection{Coleta e ensaio de laboratório}

A fim de constatar a qualidade da água reutilizada, foram coletadas três amostras. A primeira amostra foi coletada no separador de fluxo, a segunda na caixa d'água após o processo e a terceira amostra foi coletada da rede de água ofertada pela companhia de água e saneamento.

O ensaio foi orientado pela ABNT NBR 15900 para as ações de coleta e de estudo. Os recipientes utilizados foram potes de vidro com tampas de rolha de cortiço. Foram estudados em cada um dos casos 3 litros de água.

Os ensaios em laboratório consistiram em submeter as amostrar a testes de observação, cor, odor e medição de $\mathrm{pH}$. Os resultados comprovam a similaridade da água da chuva com a água fornecida pela companhia de abastecimento do município, estando apta para a utilização na produção dos blocos de concreto, conforme NBR 15900-1 que considera adequada a água de abastecimento público. Vale ressaltar que, por ser uma capital relativamente nova, Palmas-TO não possui altos índices de poluição, portanto a água coletada não sofre contaminação e não altera suas características.

Tabela 06 - Resultados obtidos na pesquisa de laboratório

(Não foi medido o pH da amostra coletada no separador.)

\begin{tabular}{c|c|c|c|c}
\hline Amostra & $\mathbf{p H}$ & Cor & Odor & $\begin{array}{c}\text { Presença de } \\
\text { impureza }\end{array}$ \\
\hline Água da chuva & 6,72 & Clara & Inodoro & Não \\
\hline Água de torneira & 6,8 & Clara & Inodoro & Não \\
\hline Água do separador & - & Escura & Não inodora & Sim \\
\hline
\end{tabular}

\section{Conclusão}

Dentre os inúmeros usos potenciais da água de chuva, o foco deste trabalho foi a utilização na Construção Civil, com destaque para a vantagem de cunho ecológico e financeiro, usando processo simples de captação, filtragem, armazenamento, distribuição e reaproveitamento.

Com os dados obtidos, pode-se concluir que a reutilização da água da chuva na produção de blocos de concreto não estrutural é um processo viável. Tendo um sistema que elimine a primeira água e trate a água coletada, o sistema se torna eficaz e vantajoso. As tabelas e gráficos apresentados mostram a viabilidade na produção e a redução de custos pela metade.

Os ensaios atestaram a qualidade da água que ao ser usada na produção garantirá blocos de concreto com a mesma qualidade da água fornecida pela companhia de água e saneamento. Com um pouco mais de investimento pode-se também armazenar água para os períodos secos reduzindo assim os gastos e a necessidade de abastecimento da companhia de água e saneamento.

A adoção de sistemas similares visa principalmente a economia de água potável, o que contribui diretamente para o atraso da escassez. Com as constantes mudanças climáticas, o ciclo da água é afetado e pensar em economizar e reutilizar a água deixou de ser opção para ser uma obrigação. Empresas que obtém esse sistema de reuso são beneficiadas e beneficiam ao mesmo tempo. Além dos ganhos econômicos e de produção, há o ganho ecológico voltado à preservação desse recurso insubstituível. Soluções sustentáveis garantem um futuro ao planeta e provam cada vez mais que natureza e sociedade podem agir em conjunto. 
Oliveira et al.: Reuso da água da chuva na produção de blocos de concreto não estrutural

\section{REFERÊNCIAS}

CORSAN. Fontes de água. Disponível em $<$ http://www.corsan.com.br/node/10>. Acesso em: 10 fev. 2015.

SANTOS, Juliana; BIBIANO, Bianca. Como São Paulo pode superar a crise hídrica. Veja Online, 2014. Disponível em: <http://veja.abril.com.br/noticia/ciencia/como-sao-paulo-pode-superar-a-crisehidrica/>. Acesso em: 10 fev. 2015.

ALVES, Liria. Conceito de pH. Brasil Escola Online. Disponível em: $<$ http://www.brasilescola.com/quimica/conceito-ph.html>. Acesso em: 12 mar. 2015.

MARCUZZO, F. F. N. et al. Mapeamento espacial, temporal e sazonal das chuvas no bioma Cerrado do estado do Tocantins. In: XV Simpósio Brasileiro de Sensoriamento Remoto, 2011, Curitiba. Anais XV Simpósio Brasileiro de Sensoriamento Remoto. São José dos Campos: INPE, 2011. v. 1. p. 5217-5224. Disponível em: <http://www.dsr.inpe.br/sbsr2011/files/p1700.pdf >. Acesso em: 15 abr. 2015.

PINTO, E. J. DE A. et al. Atlas pluviométrico do Brasil: isoietas mensais, isoietas trimestrais, isoietas anuais, meses mais secos, meses mais chuvosos, trimestres mais secos, trimestres mais chuvosos. Brasília: CPRM, 2011. 1 DVD. Escala 1:5.000.000. Equipe Executora: Adriana Burin Weschenfelder; André Luis M. Real dos Santos; Andressa Macêdo Silva de Azambuja; Carlos Eduardo de Oliveira Dantas; Denise Christina de Rezende Melo; Érica Cristina Machado; Francisco Fernando Noronha Marcuzzo; Jean Ricardo da Silva do Nascimento; José Alexandre Moreira Farias; Margarida Regueira da Costa; Paulo de Tarso R. Rodrigues; Vanesca Sartorelli Medeiros; Sistema de Informação Geográfica-SIG - versão 2.0 - atualizada em novembro/2011; Programa Geologia do Brasil; Levantamento da Geodiversidade. Disponível em: <http://www.cprm.gov.br/publique/media/Isoietas Totais Anuais 1977 2006.pdf $>$. Acesso em: 3 abr. 2013.

RIGONATTO, Marcelo. Cálculo do volume de chuvas. Brasil Escola Online. Disponível em: $<$ http://www.brasilescola.com/matematica/calculo-volume-chuvas.html $>$. Acesso em: 12 mar. 2015.

ASSOCIAÇÃO BRASILEIRA DE NORMAS TÉCNICAS. NBR 6136: Blocos vazados de concreto simples para alvenaria - Requisitos. Rio de Janeiro, 2007.

ASSOCIAÇÃO BRASILEIRA DE NORMAS TÉCNICAS. NBR 15900-1: Água para amassamento do concreto Parte 1: Requisitos. Rio de Janeiro, 2009.

ASSOCIAÇÃO BRASILEIRA DE NORMAS TÉCNICAS. NBR 15900-2: Água para amassamento do concreto - Parte 2: Coleta de amostras de ensaios. Rio de Janeiro, 2009.

ASSOCIAÇÃO BRASILEIRA DE NORMAS TÉCNICAS. NBR 15900-3: Água para amassamento do concreto - Parte 3: Avaliação preliminar. Rio de Janeiro, 2009.

CONSELHO NACIONAL DO MEIO AMBIENTE - CONAMA. Resolução no 357, de 17 de março de 2005. Dispõe sobre a classificação dos corpos de água e diretrizes ambientais para o seu enquadramento, bem como estabelece as condições e padrões de lançamento de efluentes, e dá outras providências. Disponível em: < http://www.mma.gov.br/port/conama/res/res05/res35705.pdf>. Acesso em: 28 abr, 2015. 